\title{
Research and Development of Paperless Examination System
}

$$
\text { Jing Wang }{ }^{1, a} \text { and Gao Zheng }{ }^{2, b}
$$

\author{
${ }^{1}$ School of Computer Science, Zhuhai College, Jilin University, Zhuhai, Guangdong; 519041; \\ ${ }^{2}$ Department of Electromechanical Management, China Maritime Police Academy, Ningbo, \\ Zhejiang 315801
}

a312900384@qq.com, bg197762@163.com

\begin{abstract}
Keywords: Paperless examination; Multimedia technology and application; Intelligent marking; Examination management system
\end{abstract}

\begin{abstract}
Our country's education is in a vigorous development stage. The selection of talents cannot be separated from the exam. The number of exams has made the number of exam papers amazing. The paper-based examination system has exposed the disadvantages of wasting resources and polluting the environment. The development of computer technology and database technology has injected new vitality into education. The paperless examination system is an important application of computers in the information age and is an important change in educational ideas and teaching methods brought about by modern science and technology.
\end{abstract}

\section{Introduction}

The traditional paper examination system has been used in most countries of the world, and the superiority of the examination system is obvious. However, due to the rapid increase in the number of candidates, the shortcomings of this system are gradually exposed. The traditional examination organization process has a long cycle, and the process is complex from the aspects of registration, proposition, production, issue, roll-out, examination, rating, boarding, and publishing results. Any problem in the security and confidentiality of any link will lead to disastrous consequences. The requirements for invigilators are also high, and their work is very difficult. On the basis of correct operation, it is also necessary for them to deal with all kinds of cheating in examinations. There are also paper waste, environmental pollution and other defects, and the paperless examination completely overcomes the above shortcomings and greatly shortens the examination cycle, which not only saves costs, but also improves safety and achieves fairness and justice. This paper is based on the "Multimedia Technology and Application" curriculum reform conducted by Zhuhai College of Jilin University, and describes the research and development process of the paperless examination system.

\section{Overall Needs Analysis}

The paperless examination system is based on the optimized question bank resources and uses modern information technology as a means to generate paperless test papers for random exams and to generate test scores in a timely manner. It is a diversified, new test management mode integrating test registration, test paper generation, on-machine examination, marking, achievement generation, and certificate printing [1]. The number of students enrolled in the "Multimedia Technology and Application Course" is as high as 3,000 each year. The paper-based examination format brings a lot of work pressure to teachers at the end of the semester. The paperless examination system can greatly improve examination flexibility, fairness, credibility and work efficiency [2].

In the needs analysis stage, the overall analysis of the paperless examination system, through the exchanges with users including curriculum-related teachers and students, determines the overall structure of the system. The system function module diagram is shown in Figure 1. After identity authentication, teachers can perform teacher information management, test questions management, examination management, and achievement processing. Students can take tests and give instructions. The system is divided into four functional modules, namely: score management 
module, question bank management module, user management module, and online examination module. In this stage, the detailed functions of each module are determined: The score management module mainly achieves the addition, deletion, and review of the results, and sets the management rights of different users. For example, the administrator has the highest authority, the teacher can adjust the score ratio of the test paper, and the student can check the score of the test paper. The question bank management module mainly realizes the management of the test paper, and can add, delete, change, check the test paper; The user management module is mainly a management operation for personal information by roles having different rights. The online examination module is the core module of the system and is the key to achieving a paperless exam.

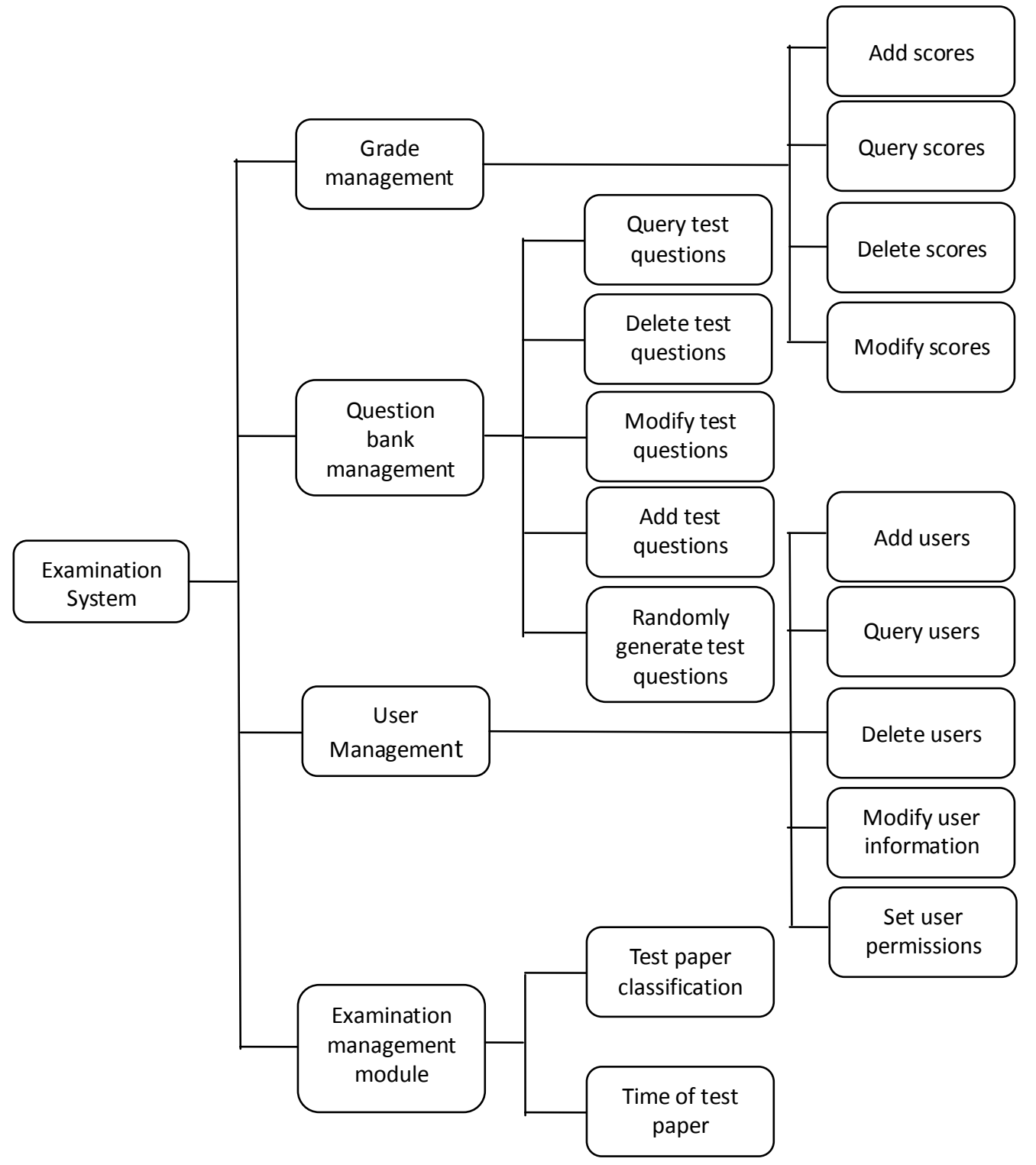

Figure 1. Finite Function module diagram of examination system

At this stage, the development model and tools that the system is expected to adopt are determined, Java language is used as the core development language, and the relational database is used as the core database for the development of the system.

\section{System Design}

In the design phase, the development mode adopted by the system was analyzed and compared. The advantage of adopting the C/S mode to develop the examination system is that it is faster and does not require IE browser for data transmission. The data is relatively safe and is suitable for 
submitting data systems in real time. The disadvantage is that each computer must be installed with a client. It is very troublesome to configure the computer. If the system is upgraded, the client needs to be updated for each computer, which increases the complexity of the system upgrade. The B/S development model can be accessed through IE browser. It is suitable for decentralized test systems. The user does not limit the place and time. It only needs to visit the IE browser to take the test. The system upgrade only needs to update the server, which saves time. However, the disadvantage is that $\mathrm{B} / \mathrm{S}$ uses IE to transmit data over the network, which may result in poor data security and may result in the loss of data. Every client's update of data needs to access a remote server, which increases the pressure on the server. After comprehensive consideration of the above two factors, according to the characteristics of multimedia technology and application courses, the $\mathrm{B} / \mathrm{S}$ model is adopted for development [3]. The system structure is shown in Figure 2.

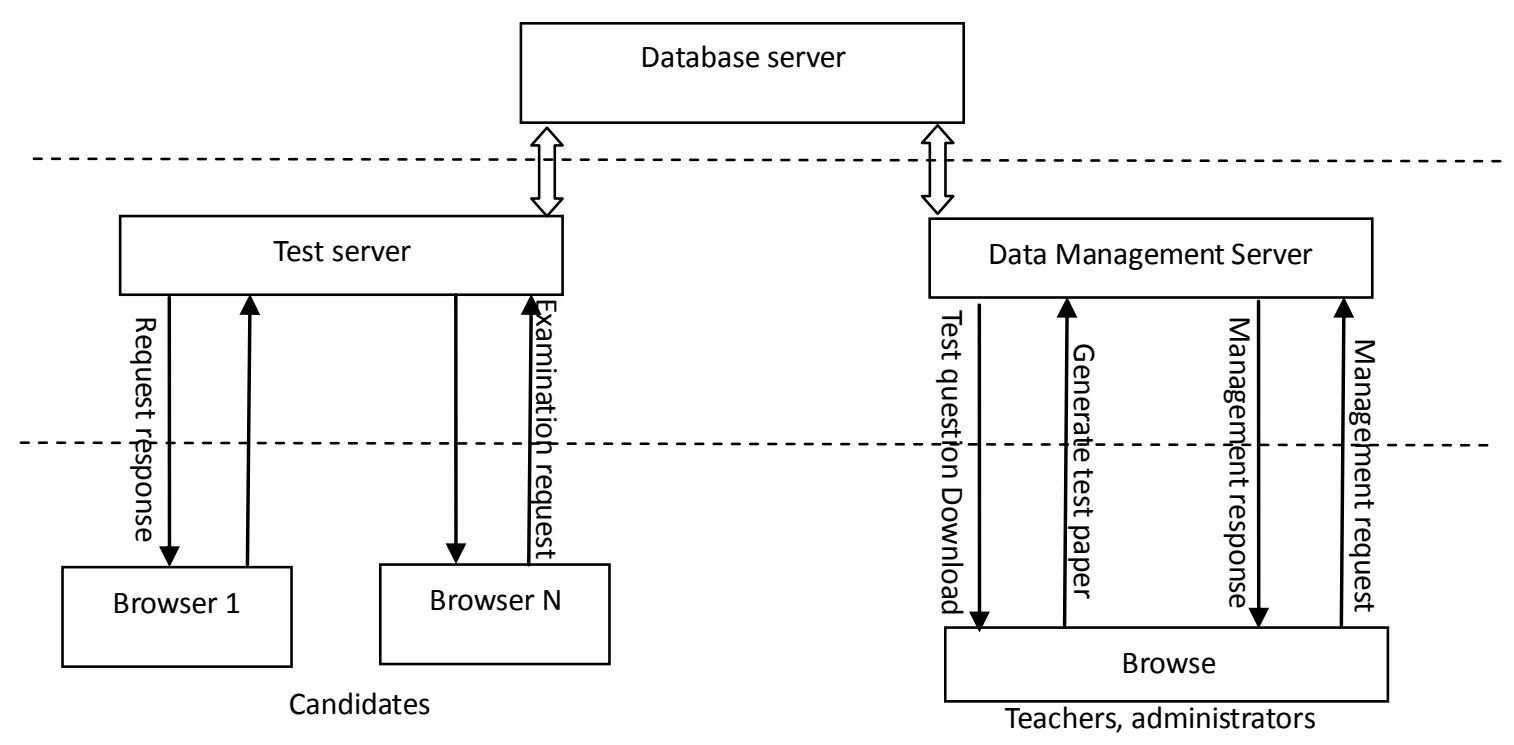

Figure 2. Finite Paperless Examination System Structure

The system design phase is divided into basic and specific tasks according to the overall requirements. The system is divided into modules, the function of each module is determined, and the calling relationship of the module and the interface of the module are determined. At this stage, the database is analyzed and designed. Based on the systematic analysis of the open paperless examination system, the system will involve examination papers, questions, system users (including students, administrators, and teachers) and several other entities. The data items involved give the overall ER diagram of the system, as shown in Figure 3. At this stage, the detailed design of the database is carried out, including the design of students' information tables, teacher information tables, test paper analysis tables, examination status tables, examination title tables, and administrator information tables [4]. 


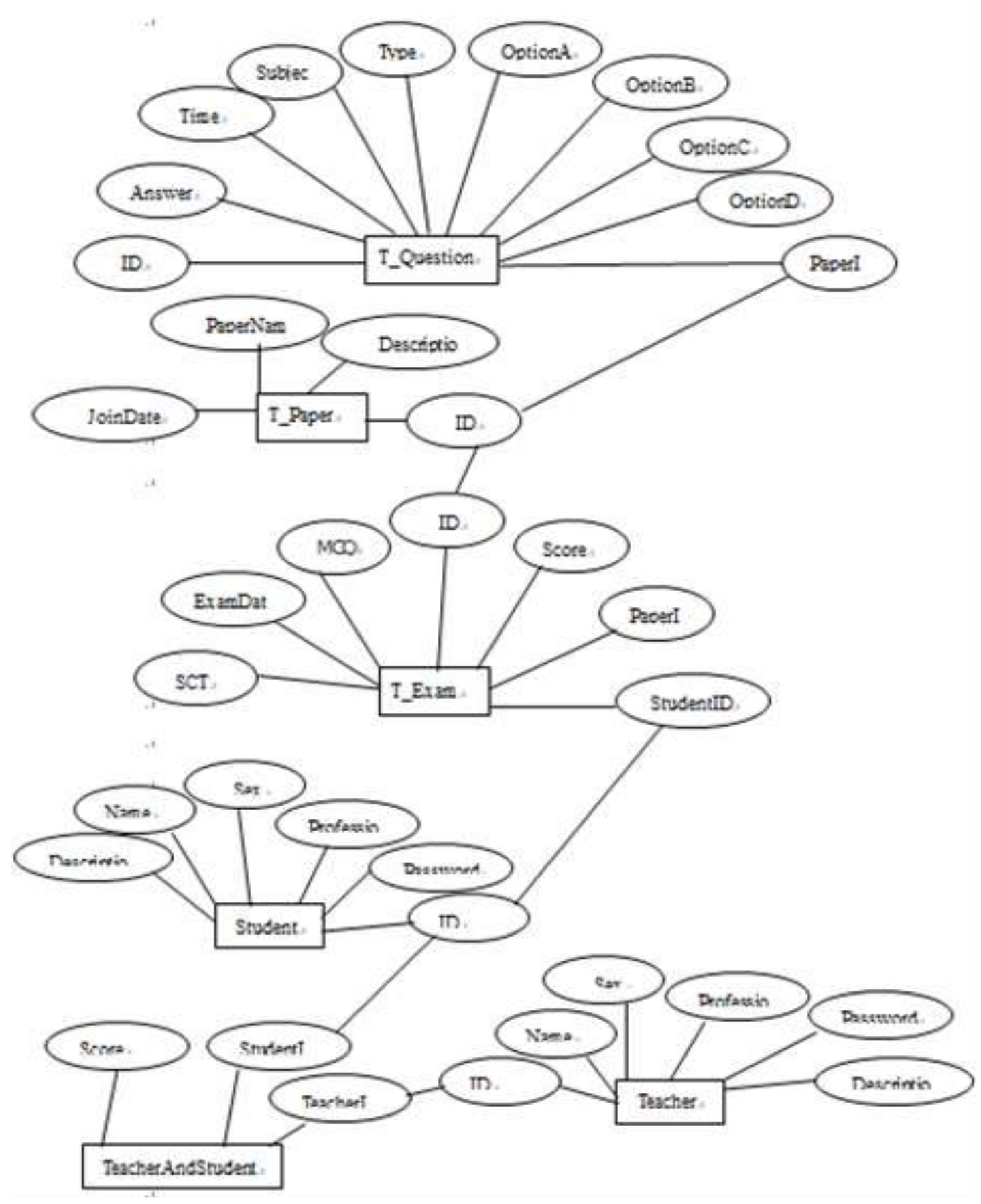

Figure 3. Finite System ER diagram

\section{System Implementation}

The system implementation stage is the development and production stage, and the programmer is responsible for the related development work. We will gradually build and implement the examination system function at this stage [5]. First, an examination information database is set up in the examination system, and each candidate is assigned a ticket number. The candidate takes the examination ticket number to perform the examination and the admission ticket number determines the candidate's identity. Then, the system is organized and an improved random sampling algorithm is adopted in the examination system [6]. The order of the question bank is disarrayed first, and random questions are taken in the subsection, which can effectively prevent the occurrence of the same problem in the same test paper and guarantee the randomness of the questions. Candidates' questions are randomly selected from the pool of questions, and the examination papers of any two candidates are not exactly the same. With the continuous construction of question banks and the 
increase of the number of questions, the possibility of repetition of test papers is getting smaller and smaller. Candidates can use the test system to determine the answer to a question after they have completed the test. Scores can be given directly [7]. The test system can automatically review the test questions, determine the scores of each question according to the candidates' answers, give the overall transcripts, and at a glance, the students can visually see the mistakes, and the teachers can also understand the mastery of the entire class and analyze the problems of the teaching process so as to improve teaching methods.

\section{System Testing and Implementation}

The purpose of the system test is to ensure that all product defects are discovered in time before the official release of the website. Testing for security can effectively prevent malicious attacks on the network from causing website data loss or website crashes [8]. We should find problems before the site is officially put into use, fix the defects, and minimize the damage. This system adopts a combination of black box testing and white box testing. The black box is used for functional testing and the white box is used for structural testing. The main test content includes: defining the scope of the test function according to the demand analysis, determining whether the user needs are fully reflected in the system, and then performing software functional testing on the unit module, including software interface, performance, stability, operational flexibility, determining whether the relationship of the modules is consistent with the demand, and finally carrying out the overall test. This paper selects one of the test results as shown in Table 1.

Table 1 Test case table for test management

\begin{tabular}{ll}
\hline fields & descriptions \\
\hline Test content & $\begin{array}{l}\text { Enter the user name to log in, select the test paper, and } \\
\text { submit the question. }\end{array}$ \\
test procedure & 1. Enter the username for the database. \\
& 2. Enter the user name that does not exist in the database. \\
& 3. Enter the username for the database, select the test paper, \\
& and click submit. \\
Expected & output \\
results & 1. Search for the drop-down box for the corresponding exam \\
& paper. \\
& 2. Show login failed. \\
& 3. Search for the appropriate test paper, select the test paper, \\
and click submit. & Online exam function is normal. \\
Test results &
\end{tabular}

\section{Conclusion}

The paperless examination system is an intelligent automatic evaluation system based on web technology. It integrates functions such as paperless examination, account management, question bank management, test paper management and score management, etc [9]. It can be made specific according to class, fractional scores and other data. The analysis gives the graphical analysis results, which is convenient for teachers to fully understand the mastery of the students, reduce the teaching workload of the teachers, and also solve the waste of resources and achieve the purpose of improving the quality of teaching. The paperless test can more effectively ensure the objectivity, impartiality and real-time nature of the test. It has the advantages of improving the efficiency of management work, saving test resources, standardizing test management, and facilitating the examination of candidates [10]. It is an implementation of scientific development. Viewing and actively building a conservation-oriented government is an inevitable trend in the future reform of the examination model. 


\section{Acknowledgements}

This paper is strongly supported by Zhuhai Computer Application Technology Advantage Research Project (2015YXXK02), Jilin University Zhuhai College "Three Levels" Faculty Construction Team (Teaching Scientific Research and Heavy Teacher) Fund Project, Guangdong Provincial Department of Education Teaching Quality and Teaching Reform Project (2017009), Jilin University Zhuhai College Innovation and Entrepreneurship Education Training Project, Jilin University Zhuhai College Teacher Education Development Fund Project (JZ2017JZB305), Key Laboratory of Symbolic Computation and Knowledge Engineering.

\section{References}

[1] Kechun Yu. Design and implementation of paperless examination system based on cloud computing[J]. Computer Knowledge and Technology, 2016, 12(02): 74-76.

[2] Hao Wang. Research on improving college students' hands-on practical ability - "Multimedia Technology Foundation and Application" course teaching reform [J]. Internet Wealth, 2010 (15) :14-15.

[3] Xinshun Guo, Xuefen Liu, Yuming Zheng. Development of Paperless Examination System[J]. Computer Applications and Software, 2005(08):131-133.

[4] Dafa Yin. Research and Development of Paperless Examination System [J]. Computer and Modernization, 2004 (03): 82-85.

[5] Z.H.Xiang and X.X.Peng: Discussion on the Construction of Three-Dimensional Teaching Resource Base Based on Big Data[J], Fujian Computer, 2016,11:163-164.(In Chinese)

[6] Ming Chen. Review of paperless examination system[J]. Computer Education, 2007(05):12-15.

[7] X.Y.Guo, W.Liu, W.W.Fu and J.Wang: Stereoscopic Teaching Practice and Thinking at the Core of Teaching Website[J], China Educational Technology, 2009,6:81-84.(In Chinese)

[8] Yongguo Wang. Design and Implementation of ACCESS Paperless Examination System Based on VB[J]. Microcomputer Applications, 2007(01):108-112.

[9] X.M.Wen, F.X.Meng and Y.C.Si: The Exploration and Practice of the Construction of the Three-Dimensional Textbook of Computer Science[J], PC Fan, 2017,4:93.(In Chinese)

[10] Y.W.Zhong: Journal of National Academy of Education Administration[J], Journal of National Academy of Education Administration, 2012,1:43-47.(In Chinese) 